\title{
In Vitro Maturation of Oocytes from Norwegian Semi-domestic Reindeer (Rangifer tarandus)
}

In vitro maturation of oocytes has been described for several species, but to our knowledge this is the first attempt to mature oocytes from reindeer in vitro. Reindeer are seasonal breeders with their main period of breeding activity starting in the beginning of October. Little knowledge exists about in vivo oocyte maturation, fertilization and development of the early embryonic stages after fertilization. The aim of the present study was to examine whether reindeer oocytes collected out of breeding season could be matured in vitro in conventional medias used for bovine oocytes.

Ovaries were collected in the beginning of September immediately after slaughter outdoors in the Jotunheimen mountains in Norway. The ovaries were then transported in saline at $20^{\circ} \mathrm{C}$ to our laboratory in Oslo. The time interval from the first ovary was collected until the oocytes were put in the incubator for maturation was $12 \mathrm{~h}$. The ovaries were small, only about $10 \mathrm{~mm}$ in diameter. No ovaries contained corpora lutea indicating that none of the animals had ovulated. Most of the ovaries contained only tiny follicles, but on a few ovaries there were big follicles of 10 $\mathrm{mm}$ in diameter which made up the whole ovary. Three of the 56 ovaries collected were totally without visible follicles. The follicle fluid was aspirated with a $23 \mathrm{G}$ needle, and the ovaries were also sliced to obtain as many follicles as possible. A total of 120 oocytes were collected after aspiration, which yielded a mean of only 2.3 oocytes per ovary. Only oocytes with an unexpanded, compact cumulus complex or complexes with an attached piece of membrana granulosa were chosen for in vitro maturation. These oocytes underwent 3 washes in modified Tyrode's medium (TLHepes) supplemented with $3 \mathrm{mg} / \mathrm{ml}$ BSA (Sigma chemical Co., St. Louis, MO), 0.2 $\mathrm{mmol} / \mathrm{l}$ pyruvate (Sigma) and $50 \mu \mathrm{g} / \mathrm{ml}$ gentamycin (Gibco, Life Technologies, Inc., Gaithersburg, MD) (Bavister et al. 1983). The maturation medium consisted of TCM 199 (Gibco) with 10\% FCS (Gibco), $2 \mu \mathrm{g} / \mathrm{ml} \mathrm{FSH}$ (NIADDK -oFSH-17), $10 \mu \mathrm{g} / \mathrm{ml} \mathrm{LH} \mathrm{(NI-}$ ADDK -oLH), $1 \mu \mathrm{g} / \mathrm{ml}$ oestradiol $17 \quad \mathrm{~B}$ (Sigma), $0.2 \mathrm{mmol} / \mathrm{l}$ pyruvate and $25 \mu \mathrm{g} / \mathrm{ml}$ gentamycin (Sirard et al. 1988). Twenty oocytes were put into $100 \mu 1$ droplets of medium covered by paraffin oil. The maturation took place in an incubator at temperature $39^{\circ} \mathrm{C}$ and in a humidified gas phase of $5 \% \mathrm{CO}_{2}$ in air. After $24 \mathrm{~h}$ the cumulus expansion was evaluated. For evaluation of nuclear maturational stages the cumulus - and granulosa cells were removed by 3 min vortexing, and the oocytes were fixed in methanol-acetic acid (3:1) for 36 $h$, stained with $10 \%$ orcein in acid alcohol and classified according to $\mathrm{Xu}$ et al. (1986).

Figures 1 and 2 show the oocytes surrounded by the cumulus - and granulosa cells before and after in vitro culture, respectively. After $24 \mathrm{~h}$ the cumulus expansion was complete including the corona radiata cells. A few of the oocytes were naked after culture. 

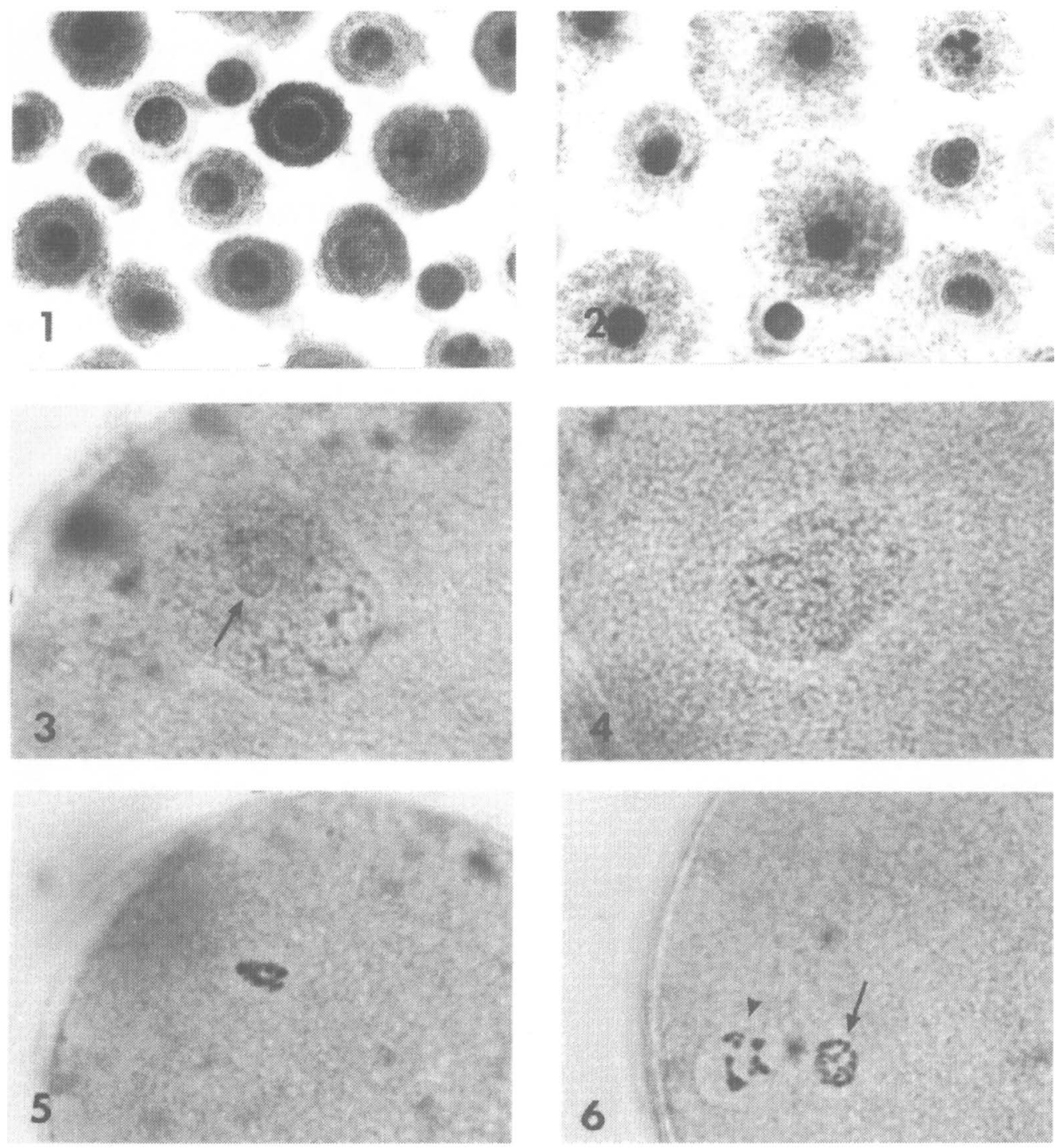

Figures 1-6. Cumulus expansion and nuclear maturational stages of oocytes from reindeer (Rangifer tarandus). 1. Oocytes before culture with no expansion of cumulus cells (50X). 2. Cumulus expansion after $24 \mathrm{~h}$ maturation (50X). 3-6. Different nuclear maturational stages after $24 \mathrm{~h}$ of maturation (400X).

3. Germinal vesicle stage (ONI). Note the nucleolus (arrow).

4. Germinal vesicle breakdown initiated (ONII).

5. Metaphase I (MI).

6. Metaphase II (MII) with metaphase plate (arrow) and polar body (arrowhead). 
A total of 84 oocytes were evaluated for nuclear maturational stages. After 24 h $71 \%$ of the oocytes had reached metaphase II (MII) with extrusion of the first polar body. A total of $22 \%$ still remained in the germinal vesicle stages $(\mathrm{GV}), 12 \%$ in oocyte nucleus stage I (ONI) and $10 \%$ in oocyte nucleus stage II (ONII). The rest of the oocytes exposed diakenesis (D) (2\%) or metaphase I (MI) (5\%) stages (Figs. 3-6).

The present study shows that in vitro maturation of oocytes from reindeer is possible in a conventional medium used for bovine oocyte maturation. Our study also shows that this can be conducted out of the breeding season, at least 1 month before the breeding season as in this experiment. In vitro maturation of sheep oocytes in the nonbreeding season has been previously reported (Pugh et al. 1991). These authors also showed that sheep embryo production is possible during the nonbreeding season.

Another important observation is that the reindeer ovaries could be kept at $20^{\circ} \mathrm{C}$ for 10 $\mathrm{h}$ before the oocytes were recovered and still $70 \%$ of the oocytes had completed oocyte maturation after culture, indicating a high resistance of reindeer oocytes to ambient temperature. Usually cow ovaries are kept at 30$37^{\circ} \mathrm{C}$ during transport, but Gordon \& $\mathrm{Lu}$ (1990) showed that cow ovaries could be held at $20^{\circ} \mathrm{C}$ for $8 \mathrm{~h}$ before oocytes were recovered without any effect on maturation - and fertilization results. It would be interesting to see if a reduced transport time for reindeer ovaries would improve the success rate, but this will be difficult to perform in practice. Also, the success rate will possibly be improved by collection of oocytes within the breeding season. A successful maturation of oocytes can with certainty only be judged from results obtained after fertilization and further development. Therefore, further in vitro experiments will be attempted in this species.

\section{Acknowledgements}

This work was financially supported by the Norwegian Agricultural Research Council. The authors also thank the National Institute of Diabetes and Digestive and Kidney Diseases, the Center for Population Research of the National Institute of Child Health and Human Development, the Agricultural Research Service of the U.S. Department of Agriculture, and University of Maryland School of Medicine for providing ovine FSH and $\mathrm{LH}$.

\section{A. Krogences, E. Ropstad, T. Nilsen}

Department of Reproduction and Forensic Medicine, Norwegian College of Veterinary Medicine, Oslo, Norway.

\section{$\emptyset$. Pedersen}

Department of Animal Sciences, Norwegian Agricultural University, Ås, Norway.

\section{Forsberg}

Department of Clinical Chemistry, Swedish University of Agricultural Sciences, Uppsala, Sweden.

\section{References}

Bavister BD, Leibfried ML, Lieberman G: Development of preimplantation embryos of the golden hamster in a defined culture medium. Biol. Reprod. 1983, 28, 235-247.

Gordon I, $\mathrm{Lu} \mathrm{KH}$ : Production of embryos in vitro and its impact on livestock production. Theriogenol. 1990, 33, 77-87.

Pugh PA, Fukui Y, Tervit HR, Thompson JG: Developmental ability of in vitro matured sheep oocytes collected during the nonbreeding season and fertilized in vitro with frozen ram semen. Theriogenol. 1991, 36, 771-778.

Sirard MA, Parrish JJ, Ware CB, Leibfried-Rutledge $C B$, First $N L$ : The culture of bovine oocytes to obtain developmentally competent embryos. 1988, Biol. Reprod. 39, 546-552.

$X u K P$, Greve T, Smith S, Hyttel P: Chronological changes of bovine follicular oocyte maturation in vitro. Acta vet. scand. 1986, 27, 505-519.

(Received October 20, 1992; accepted January 4, 1993).

Reprints may be requested from: A. Krogenæs, Department of Reproduction and Forensic Medicine, Norwegian College of Veterinary Medicine, P.O. Box 8146, N-0033, Oslo 1, Norway. 